\title{
Biofilm Electrode Method for Degradation of P-Nitrophenol
}

\author{
Junsheng Hu, Huan Wang, and Zhenxin Zhang
}

\begin{abstract}
With p-nitrophenol as the target contaminant, the influence of various factors: aeration rate, electrolyte concentration, and initial $\mathrm{pH}$ to chemical oxygen demand (COD) and p-nitrophenol (PNP) removal efficiency of the wastewater containing nitro phenol were studied in experiments with the homemade biofilm electrodes reactor. Research shows that with the increasing of aeration rate, electrolyte concentration, or initial pH, COD and PNP removal efficiency of the wastewater showed a decreasing trend after the first increase. The best experimental conditions of nitrophenol degradation adopted biological membrane electrode method, under the conditions of electrolysis time of $4 \mathrm{~h}$, impressed voltage of $6 \mathrm{~V}$ and initial concentration of $200 \mathrm{mg} / \mathrm{L}$, is aeration rate of $0.2 \mathrm{~m}^{3} / \mathrm{h}$, electrolyte concentration of $1.0 \mathrm{~g} / \mathrm{L}$ and initial $\mathrm{pH}$ of 7 . Under the best conditions, the PNP nitrophenol wastewater removal efficiency was $85.85 \%$.
\end{abstract}

Index Terms-Biofilm electrode, chemical oxygen demand, electrochemical oxidation, p-nitrophenol.

\section{INTRODUCTION}

The Biological membrane electrode method is a new water treatment technology developed in recent years, in which microorganisms and electrochemical work together to remove pollutants after formation of biofilms on the electrode surface fixed the microorganisms[1]-[6]. Currently, the main methods of removing nitrophenol are microbial degradation and the chemical oxidation method [7]-[8]. In this paper, based on self-made biological membrane electrode reactor with activated carbon fiber as an-ode and the biofilm electrode formed by acclimatized microorganisms adsorbed on activated carbon fiber electrode electrochemical and biochemical mechanism are combined to degrade p-nitrophenol waste water. Then in the experiment, the removal effects of p-nitrophenol in wastewater of aeration and electrolyte concentration and initial $\mathrm{PH}$ value, were studied to determine the best treatment condition.

\section{EXPERIMENT}

\section{A. Apparatus and Reagents}

Composition of simulated p-nitrophenol wastewater: 0.1 $\mathrm{G} / \mathrm{L}$ p-nitrophenol; $0.7 \mathrm{G} / \mathrm{L}$ ammonium sulfate; $0.03 \mathrm{G} / \mathrm{L}$ magnesium sulfate; $0.02 \mathrm{G} / \mathrm{L}$ anhydrous calcium chloride,

Manuscript received June 30, 2016; revised August 30, 2016. This work was supported by the Science research project of Educational Commission of Liaoning Province of China (L2014229).

The authors are with School of municipal and environmental engineering, Shenyang Jianzhu University, Shenyang, Liaoning Province, China (e-mail: jusheng.hu@163.com,876321405@qq.com,1056439499@qq.com).
$0.2 \mathrm{G} / \mathrm{L}$ potassium phosphate dibasic; sodium dehydrogenase phosphate $0.08 \mathrm{G} / \mathrm{L}$; and $\mathrm{pH} 6.5$ to 7.5 .

Instruments used in this experiment are shown in the Table I:

TABLE I: INSTRUMENTS USED IN THE EXPERIMENT

\begin{tabular}{cc}
\hline \hline Name & Type \\
\hline Visible Spectrophotometer; & WFJ2100 \\
Gas flow counter & DK800-2F \\
pH Meter & HI98127 \\
electronic Balance & FA1004N \\
Electronic multi-purpose furnace & Fuxing/FX \\
Air compressor & GSP-77-03 \\
DC power supply & WYJ-302B2 \\
\hline \hline
\end{tabular}

\section{B. Analytical Method}

Visible spectrophotometry was used to determine p-nitrophenol (PNP) concentration of the solution. It was found that the visible spectrophotometer has a strong absorption to PNP at $400 \mathrm{~nm}$ wavelength, and at lower concentrations, they have a good linear relationship between absorbency and concentration. COD was measured with the fast closed catalytic decomposition method [9].

\section{Experimental Apparatus}

The Biofilm-electrode reactor device is shown in Fig.1. The reactor is made of Plexiglas. Its size is $18.0 \mathrm{~cm} \times 6.0 \mathrm{~cm}$ $\times 12.0 \mathrm{~cm}$. There are four $2 \mathrm{~mm}$ card-slots built in the reactor for fixing the activated carbon fiber electrode and biofilm electrode. The four active-carbon-fibers, thickness of $2 \mathrm{~mm}$, are placed isometric cross within the card slot, respectively, on both sides reinforced with $8.0 \mathrm{~cm} \times 0.5 \mathrm{~cm} \times 0.1 \mathrm{~cm}$ stainless steel. And both sides of the glass cylinder in the reactor are used to fix the gas distribution panel. Therefore you can keep up to date with demolition, cleaning the gas distribution panel.

\section{Preprocess and Preparation of the Electrode}

The activated carbon fiber electrode are cut into $4.5 \mathrm{~cm} \times$ $4.5 \mathrm{~cm}$ piece, immersed and washed three times with deionized water, then, dried in $393.15 \mathrm{~K}$ for $2 \mathrm{~h}$ for spare. The stainless steels are put in 0.5 dilute sulphuric acids soaking for $3 \mathrm{~h}$ to remove oil, dust and other pollutants from the surface, and then washed over and over again with distilled water, until the water turn into neutral, at last are dried naturally. And then divide the stainless steel plates into $8 \mathrm{~cm}$ $\times 0.5 \mathrm{~cm}$ rectangular pieces playing a role in reinforcement electrode and accelerated electrically conductive.

Natural absorption method is used to prepare the biofilm-electrode. The activated sludge was taken from a sewage treatment plant in Shenyang, China. The first step is dumping the supernatant after the first precipitation then 
taking the layer of sludge in the aeration tank without any nutrients for two days. Then add the nutrient solution prepared in Advance with the target pollutants as the sole carbon source to the container to culture. This stage last for 10 days with adding nutrient solution to the container every 2 days. When sludge microorganisms gradually adapt to low concentrations of p-nitrophenol and form the logarithmic growth trend, inoculate activated carbon fiber electrode surface with the sludge microorganisms. In the next stage add nutrient solution to the container on a regular basis, increasing concentration of pretreatment material gradually. Then select the sludge microorganisms which own good treatment effect with micro electric current domestication. Microorganisms with the capability of flocculation will adsorb to the electrode surface forming the biofilm, and the whole process takes about 30 days.

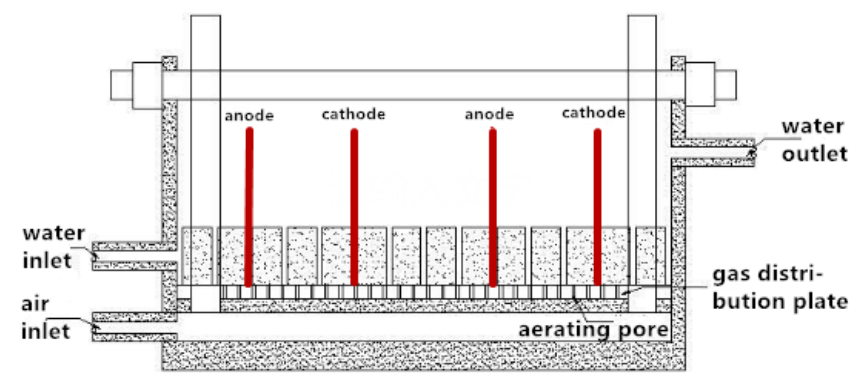

Fig. 1. Biofilm electrode reactor.

\section{RESUlTS AND DISCUSSIONS}

\section{A. Effect of Aeration on Degradation of P-Nitrophenol Wastewater}

The objective of this experiment is the treatment of p-nitrophenol wastewater degrading simulated nitrophenol wastewater with the initial concentration of $200 \mathrm{mg} / \mathrm{L}$, under the conditions: the electrolytic time $4 \mathrm{~h}, \mathrm{PH} 7$, the electrolyte concentration of $1 \mathrm{~g} / \mathrm{L}$, and the applied voltage to $6 \mathrm{~V}$. Then study on the effect on the PNP removal and COD removal rate respectively of different aeration intensity: $0.1 \mathrm{~m}^{3} / \mathrm{h}, 0.2$ $\mathrm{m}^{3} / \mathrm{h}, 0.3 \mathrm{~m}^{3} / \mathrm{h}$ and $0.4 \mathrm{~m}^{3} / \mathrm{h}$.

Fig. 2 and Fig. 3 show that under different aeration conditions, with the reaction time increasing, PNP removal rate and the rate of COD removal in waste water have been increased. And with the increasing aeration, PNP removal rate and the removal of COD in waste water are both rendered after the first increase to reduce trend. In the 0.2 $\mathrm{m}^{3} / \mathrm{h}$ aeration condition, removal rate PNP and COD reaches the biggest and removal effect is the best. And when the experiment was for 4 hours, PNP removal rate is $81.23 \%$ and COD removal rate is $68.17 \%$. Besides, in the $0.2 \mathrm{~m}^{3} / \mathrm{h}$ aeration condition, because of insufficiently stirring of the solution leading to the solution transfer rate is low, makes dissolved oxygen and PNP of the electrode surface get inadequate supplementary in time, to the detriment of respiration of p-nitrophenol degradation bacteria and electro-catalytic reaction. And in the $0.4 \mathrm{~m}^{3} / \mathrm{h}$ aeration condition, owing to too much bubble in the electrolysis slot p-nitrophenol cannot get enough contacts with the electrode surface and then the amount of $\mathrm{H}_{2}$ absorbed in the electrode surface is much smaller directly leading to the reduction of the amount of $\mathrm{H}_{2}$ that combine with microorganisms. So the poor effects of PNP removal rate and COD removal rate will be got. Therefore, $0.2 \mathrm{~m}^{3} / \mathrm{h}$ aeration is best for degradation of p-nitrophenol.

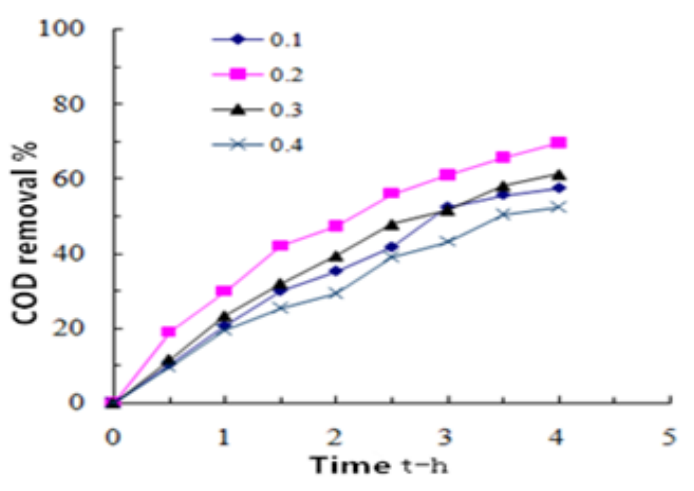

Fig. 2. Effect of aeration on COD removal.

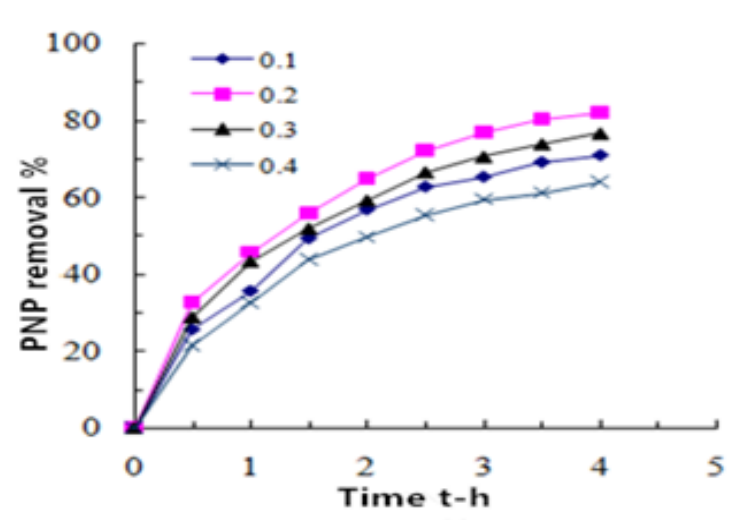

Fig. 3. Effect of aeration on PNP removal.

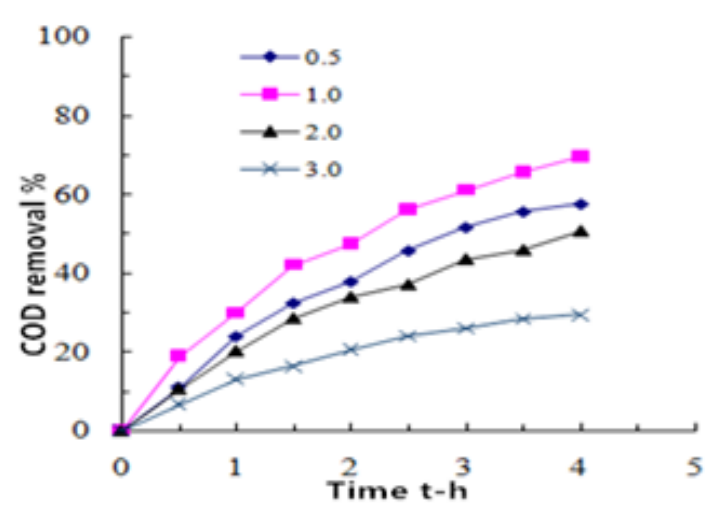

Fig. 4. Effect of electrolyte concentrations on COD removal.

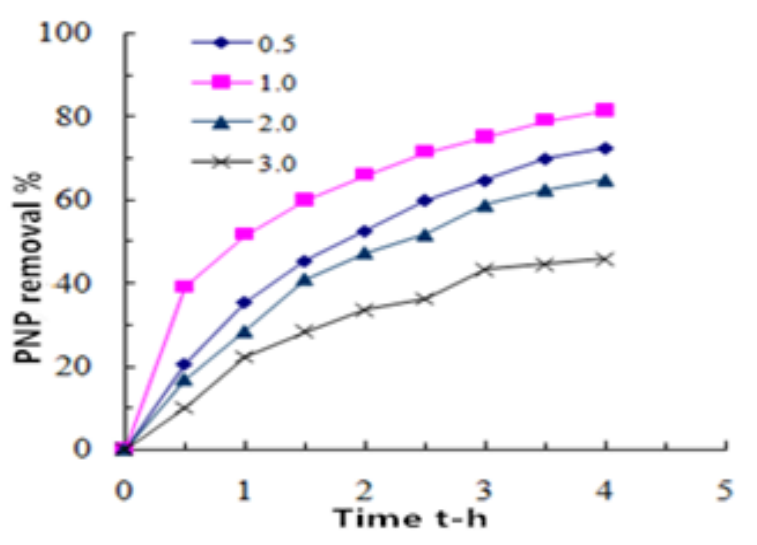

Fig. 5. Effect of electrolyte concentrations on PNP removal. 


\section{B. Effect of Electrolyte Concentration on Degradation of P-Nitrophenol Wastewater}

The objective of this experiment is the treatment of p-nitrophenol wastewater degrading simulated nitro-phenol wastewater with the initial concentration of $200 \mathrm{mg} / \mathrm{L}$, under the conditions: the electrolytic time $4 \mathrm{~h}, \mathrm{PH} 7$, and the applied voltage to $6 \mathrm{~V}$. Then study on the effect on the PNP removal and COD removal rate respectively of different electrolyte concentrations: $0.5 \mathrm{~g} / \mathrm{L}, 1 \mathrm{~g} / \mathrm{L}, 2 \mathrm{~g} / \mathrm{L}$ and $3 \mathrm{~g} / \mathrm{L}$.

Fig. 4 and Fig. 5 shows that in conditions of different electrolyte concentration, PNP removal rate and the removal of COD in waste water are both rendered after the first increase to reduce trend. In the $1 \mathrm{~g} / \mathrm{L}$ electrolyte concentrations condition, removal rate of PNP and COD reaches the biggest and removal effect is the best. And when the experiment was for four hours, PNP removal rate is $81.51 \%$ and COD removal rate is $70.45 \%$. If the electrolyte concentration is too low, the current is very small, and electron transfer is affected, then the degradation rate will be lower. SO, appropriately increasing the concentration of the electrolyte can effectively improve the treatment effect of electrochemical section. When electrolyte concentration is too high, as the electrolyte sodium sulfate concentration increases, PNP removal rate and COD removal rate in wastewater but become lower. From the perspective of biology, high salinity and currents are not suitable for microbial growth, then do harm to the degradation effect of Biofilm-Electrode Microbial. Except that, from the electrochemical point of view, electrolyte concentration reaches a certain point, and continues to grow, which will enhance the interaction between the electrolyte ions. Then it leads to lower electrical conductivity. And too much electrolyte content makes a large number of $\mathrm{SO}^{2-}$ adsorb on the anode surface, hindering the electrode reaction of hydroxyl radicals for $\mathrm{SO}^{2-}$ can reaction with hydroxyl radicals, thereby reducing hydroxyl radical concentration on the electrode surface [10]:

$$
\mathrm{SO}_{4}^{2-}+\cdot \mathrm{OH}+\mathrm{H}^{+} \rightarrow \mathrm{SO}_{4}^{-}+\mathrm{H}_{2} \mathrm{O}
$$

Therefore, electrolyte concentration is best to take $1.0 \mathrm{~g} / \mathrm{L}$ for degradation of p-nitrophenol.

\section{Effect of Initial PH on Degradation of P-Nitrophenol Wastewater}

The objective of this experiment is the treatment of p-nitrophenol wastewater degrading simulated nitro-phenol wastewater with the initial concentration of $200 \mathrm{mg} / \mathrm{L}$, under the conditions: the electrolytic time $4 \mathrm{~h}$, the electrolyte concentration of $1 \mathrm{~g} / \mathrm{L}$, and the applied voltage to $6 \mathrm{~V}$. Then study on the effect on the PNP removal and COD removal rate respectively of different initial PH: 5, 6, 7, 8 and 9.

Fig. 6 and Fig. 7 show that in conditions of different initial $\mathrm{PH}, \mathrm{PNP}$ removal rate and the removal of COD in wastewater are both rendered after the first increase to reduce trend. In the initial PH: 7 conditions, removal rate of PNP and COD reaches the biggest and removal effect is the best. And when the experiment was for four hours, PNP removal rate is $84.37 \%$ and COD removal rate is $71.35 \%$. This is because in the case of excessively higher or lower $\mathrm{pH}$ values, on the one hand, in the experiment the Nitro-phenol-degrading bacteria attached to the Biofilm-Electrode adapt to the conditions, and enzyme activity is stifled against oxidative degradation of p-nitrophenol. The other hand, too high or too low $\mathrm{PH}$ value influents the dissociation balances of p-nitrophenol in the aqueous solution. If $\mathrm{PH}$ value is too low, a lot of free $\mathrm{H}+$ in solution make the negatively charged ions in solution difficultly reach the cathode surface, leading to the concentration of p-nitrophenol on the cathode surface is not high to the detriment of the catholic reaction. While the $\mathrm{pH}$ value is too high, a lot of free $\mathrm{OH}$ - in solution make the polarization intensify, resulting in reduction of the PNP and the COD removal rate in wastewater:

$$
2(\cdot \mathrm{OH})_{a d s} \rightarrow \mathrm{O}_{2}+2 \mathrm{H}^{+}+2 \mathrm{e}^{-}
$$

Therefore, the initial PH is best to take 7 for degradation of p-nitrophenol.

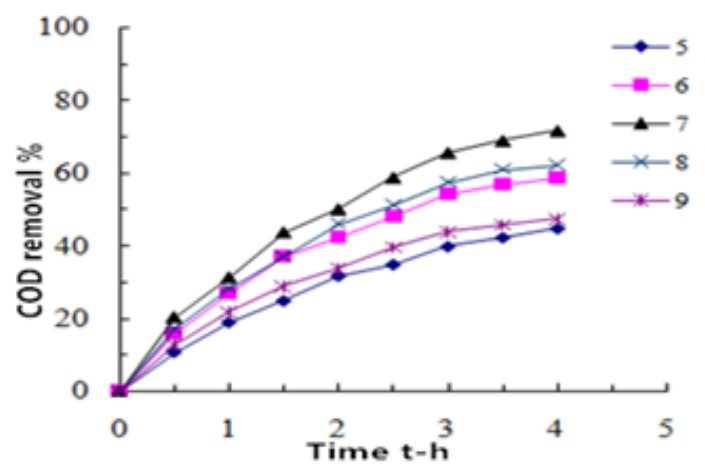

Fig. 6. Effect of initial PH on COD removal.

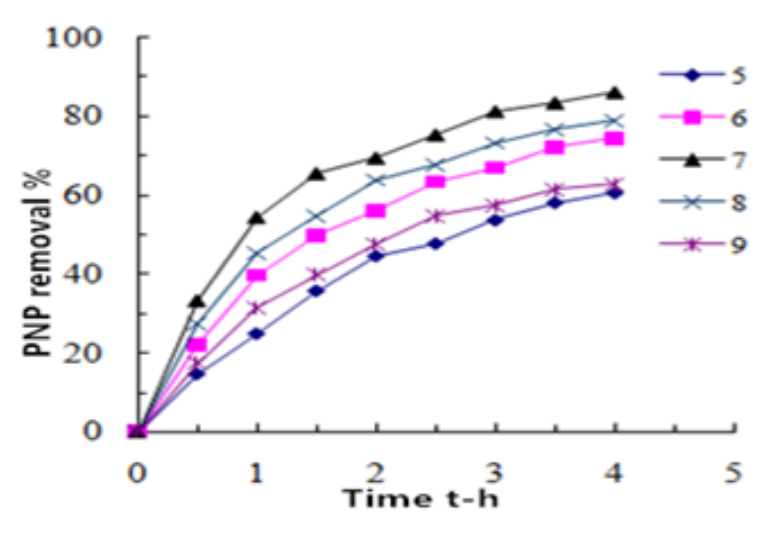

Fig. 7. Effect of initial PH on PNP removal.

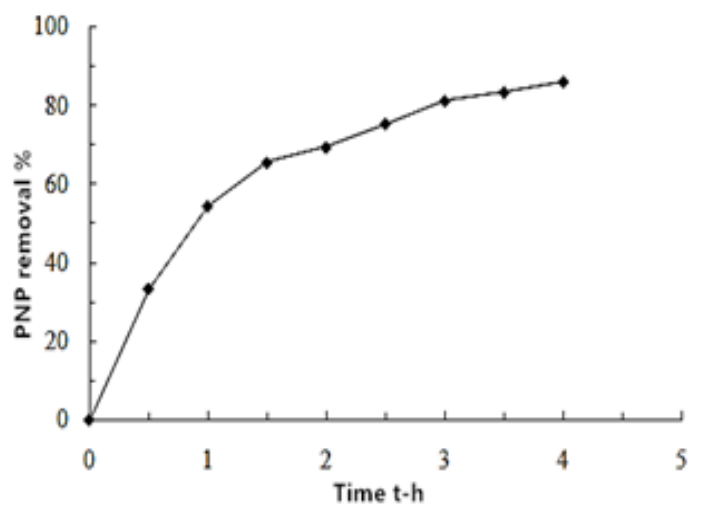

Fig. 8. PNP removal. 


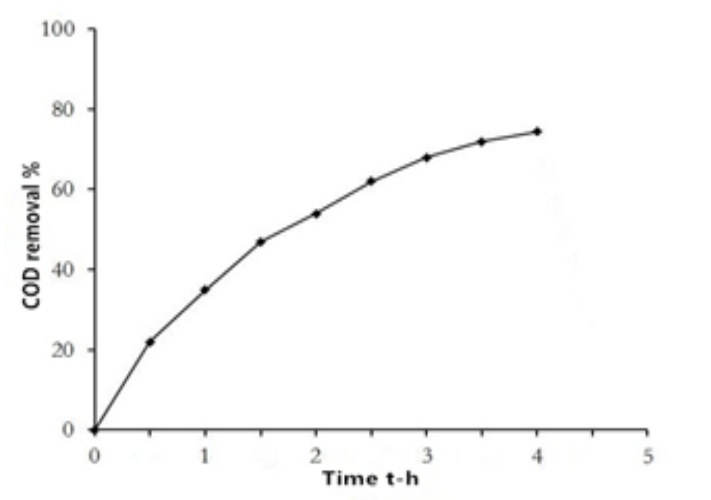

Fig. 9. COD removal.

As the figures put, in the additional experiments removal of PNP is $85.85 \%$, and COD removal rate is $74.36 \%$. Therefore the reactor and methods are very effective for degradation of p-nitrophenol in the waste water. The study laid the foundation for the Biofilm-Electrode technique in the practical application of wastewater treatment.

\section{Additional Experiments}

At room temperature in the follow conditions: initial concentration of p-nitrophenol wastewater is $200 \mathrm{mg} / \mathrm{L}$, applied voltage is $6 \mathrm{~V}$, the aeration is $0.2 \mathrm{~m}^{3} / \mathrm{h}$, electrolyte concentration is $1 \mathrm{~g} / \mathrm{L}$, and the initial $\mathrm{PH}$ value is 7 , additional experiments are performed to study the PNP removal rate and COD removal rate. Results are shown in Fig. 8 and Fig. 9 respectively.

\section{CONCLUSIONS AND OUTLOOK}

1) The Biofilm-Electrode can effectively remove p-nitrophenol in wastewater, greatly improve the degradation rate, and has good application prospects

2) Studies indicate that, as aeration rate, electrolyte concentration and initial $\mathrm{pH}$ values increasing, PNP removal rate and the removal of COD in wastewater are both rendered after the first in-crease to reduce trend.

3) Under the conditions: the initial concentration of 200 $\mathrm{mg} / \mathrm{L}$, the electrolytic time $4 \mathrm{~h}$, and the applied voltage to $6 \mathrm{~V}$, by Biofilm-Electrode Method for the degradation of p-nitrophenol the best experimental conditions are: aeration rate of $0.2 \mathrm{~m}^{3} / \mathrm{h}$, electrolyte concentration of 1.0 $\mathrm{g} / \mathrm{L}$ and initial $\mathrm{pH}$ of 7 . Under the best conditions, the PNP nitrophenol wastewater removal efficiency was $85.85 \%$, and COD removal rate is $74.36 \%$.

Treatment technology of Biofilm-Electrode owns high load, small footprint, easy operation and maintenance, good water quality and other characteristics [11]-[13]. Application prospect in waste water treatment process has been widely optimistic, but some problems still exist, for ex-ample, the problem of anode of fixing microbes. If certain microorganisms can be fixed on the anode, the scope of application of Biofilm-Electrode Method to a large extent will be broadening.

\section{REFERENCES}

[1] J. J. Tang, J. S. Guo, F. Fang, Y. P. Chen, L. J. Lei, and L. Yang, "Oxidation behavior of ammonium in a 3-dimensional biofilm-electrode reactor," Journal of Environmental Sciences, 2013, 25(12), pp. 2403-2409.

[2] M. Kuroda, T. Watanabe, and Y. Umedu, " Simultaneous COD removal and denitrification of wastewater by bio-electro reactors," Water Sci Techno, 1997, vol. 35, no. 8, pp. 161-168.

[3] Y. Sakakibara and M. Kuroda, "Electric prompting and control of denitrification," Biotechnology and Bioengineering, 1993, vol. 42, no. 2, pp. 535-537.

[4] X. Wang, H. B. Lin, J. Y. Wang et al., "Influence of the biofilm formation process on the properties of biofilm electrode material," Materials Letters, 2012, vol. 78, pp. 174-176.

[5] X. N. Zhang, W. M. Huang, X. Wang et al., "Feasibility and advantage of biofilm-electrode reactor for phenol degradation," Journal of Environmental Sciences, 2009, vol. 2, no. 19, pp. 1181-1185.

[6] B. Kang, W. M. Huang, Y. J. Zhang et al., "Studies on the 4-Amion-dimethyl-aniline hydrochloride degrade by a bio-electro reactor," Chem J Chinese Universities, 2007, vol. 28, no. 3, pp. 556-558.

[7] L. H. Cheng, J. L. Huang, and L. Wang, "Degradation of p-Nitrophenol by UV/Fe (C2O4)33-/H2O2, UV/Fenton and Fen-ton," Journal of Harbin University of C. E. \&Architecture, 2001, vol. 34, no. 2, pp. 74-78.

[8] Y. Y. Li, "Isolation and characterization of a p-Nitrophenol degrading bacterium and its degrading ability, "China, Shandong Agricultural University, 2008.

[9] SEPA of China, Water and Wastewater Determination Methods (Fourth Edition, Beijing, China, Chinese Environmental Science Press, 2002.

[10] M. Abdullah, G. K. Low, and R. W. Matthews, "Effect of common inorganic anions on rates of photo catalytic oxidation of organic carbon over illuminated titanium dioxide," J. PPhys. Chem, 1990, pp. 6820-6825.

[11] L. Zhang, J. F. Lang, and S. S. Niu, "Biofilm research progress in wastewater treatment," Water Science and Engineering Technology, 2010, pp. 38-41.

[12] Y. Luo and S. Wang, "Progress in research and application of treating surface water by bio-film technology," Environmental Science and Management, 2011, vol. 36, no. 3, pp. 69-72.

[13] Z. X. Zhang and Y. Qian. "New technology of biological wastewater treatment,"Beijing, China, Tsinghua University Press, 2004.

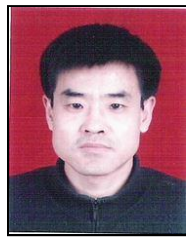

Junsheng Hu was born in Liaoning Province, China in Dec, 1968. He received his bachelor degree in 1991 from Dalian University of Technology, Dalian, China and he received his master degree in 2001 from Harbin Institute of Technology, Harbin, China. And he is with School of municipal and environmental engineering, Shenyang Jianzhu University, Shenyang, Liaoning Province, China as a professor.

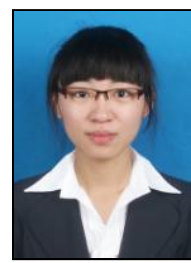

Huan Wang is a postgraduate student in School of municipal and environmental engineering in Shenyang Jianzhu University, Shenyang, Liaoning Province, China. She is currently doing her research on "Theory and technology of water pollution control" under the supervision of Prof. Hu for the completion of her master Degree.

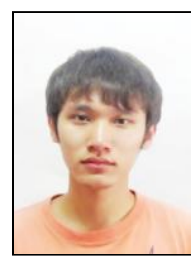

Zhenxin Zhang is a postgraduate student in School of municipal and environmental engineering in Shenyang Jianzhu University, Shenyang, Liaoning Province, China. $\mathrm{He}$ is currently doing his research on "Theory and technology of water pollution control" under the supervision of Prof. Hu for the completion of his master Degree. 